\title{
In vitro evidence that hyperglycemia stimulates tumor necrosis factor- $\alpha$ release in obese women with polycystic ovary syndrome
}

\author{
F González ${ }^{1}$, N S Rote ${ }^{1}$, J Minium ${ }^{1}$ and J P Kirwan ${ }^{2}$ \\ ${ }^{1}$ Department of Reproductive Biology and ${ }^{2}$ Department of Medicine, Schwartz Center for Metabolism and Nutrition, Case Western Reserve University School \\ of Medicine, Cleveland, Ohio 44109, USA \\ (Requests for offprints should be addressed to F González, MetroHealth Medical Center, Department of Obstetrics and Gynecology, Hamann S4-44, \\ 2500 MetroHealth Drive, Cleveland, Ohio 44109, USA; Email: fgonzalez@metrohealth.org)
}

\begin{abstract}
Women with polycystic ovary syndrome (PCOS) are often insulin resistant and have chronic low-level inflammation. The purpose of this study was to determine the effects of hyperglycemia in vitro on tumor necrosis factor (TNF)- $\alpha$ release from mononuclear cells (MNC) in PCOS. Twelve reproductive-age women with PCOS (six lean, six obese) and 12 age-matched controls (six lean, six obese) were studied. Insulin sensitivity $\left(\mathrm{IS}_{\mathrm{HOMA}}\right)$ was estimated from fasting levels of glucose and insulin and percent truncal fat was determined by dual energy absorptiometry (DEXA). TNF $\alpha$ release was measured from MNC cultured under euglycemic and hyperglycemic conditions. $\mathrm{IS}_{\mathrm{HOMA}}$ was higher in obese women with PCOS than in lean women with PCOS (student's $t$-test; $73 \cdot 7 \pm 14 \cdot 8$ vs $43 \cdot 1 \pm 8 \cdot 6, P<0 \cdot 05$ ), but similar to that of obese controls. IS HOMA $_{\text {Has }}$ positively correlated
\end{abstract}

with percent truncal fat $(r=0 \cdot 57, P<0 \cdot 04)$. Obese women with PCOS exhibited an increase in the percent change in $\mathrm{TNF} \alpha$ release from MNC in response to hyperglycemia compared with obese controls $(10 \mathrm{mM}, 649 \pm 208 \%$ vs $133 \pm 30 \%, \quad P<0 \cdot 003 ; 15 \mathrm{mM}, 799 \pm 347 \%$ vs $183 \pm$ $59 \%, P<0 \cdot 04)$. The TNF $\alpha$ response directly correlated with percent truncal fat $(r=0.45, P<0.03)$ and $\mathrm{IS}_{\mathrm{HOMA}}$ $(r=0.40, P<0.05)$ for the combined groups, and with plasma testosterone $(r=0.60, P<0.05)$ for women with PCOS. MNC of obese women with PCOS exhibit an increased TNF $\alpha$ response to in vitro physiologic hyperglycemia. MNC-derived TNF $\alpha$ release may contribute to insulin resistance and hyperandrogenism, particularly when the combination of PCOS and increased adiposity is present.

Journal of Endocrinology (2006) 188, 521-529

\section{Introduction}

Polycystic ovary syndrome (PCOS) is one of the most common female endocrinopathies, affecting $4-10 \%$ of reproductive-age women (Knochenhauer et al. 1998, Dunaif 1999). The disorder is characterized by hyperandrogenism, chronic oligo- or anovulation, and polycystic ovaries, with two out of these three findings required to diagnose PCOS (Rotterdam Group 2004a, 2004b). As many as $70 \%$ of women with PCOS exhibit insulin resistance, with the compensatory hyperinsulinemia considered to be the cause of the hyperandrogenism (Burghen et al. 1980, Nestler et al. 1998, Goodarzi \& Korenman 2002, Rotterdam Group 2004a, 2004b). In addition, women with PCOS are often obese, a condition strongly associated with insulin resistance and hyperglycemia (Kolterman et al. 1980, Ciaraldi et al. 1981).

Hyperglycemia can contribute to the development of insulin resistance and impaired insulin secretion in a phenomenon known as 'glucose toxicity' (Rossetti et al. 1990, Yki-Jarvinen 1992). It is recognized that these effects may be the exaggeration of normal regulatory responses to increases in circulating glucose. We have shown that in PCOS, hyperglycemia causes an increase in reactive oxygen species (ROS) generation from peripheral blood mononuclear cells (MNC) (González et al. 2006). ROSinduced oxidative stress is a known activator of nuclear factor $\mathrm{\kappa B}(\mathrm{NF \kappa B})$, a proinflammatory transcription factor that promotes tumor necrosis factor- $\alpha$ (TNF $\alpha$ ) gene transcription (Barnes \& Karin 1997, Mohanty et al. 2000, Evans et al. 2002). TNF $\alpha$ is an established mediator of insulin resistance (Hotamisligil et al. 1994). Thus, increased TNF $\alpha$ release from MNC in response to hyperglycemia may be an underlying mechanism for insulin resistance in PCOS.

In vitro studies have shown that TNF $\alpha$ can truncate insulin receptor signaling in all insulin-sensitive tissues (Feinstein et al. 1993, Hotamisligil et al. 1994, Del Aguila et al. 1999). In obesity-related diabetic syndromes, TNF $\alpha$ is overexpressed in adipose tissue and causes increased serine phosphorylation of insulin receptor substrate-1 (IRS-1) (Hotamisligal et al. 1993, 1995, Rui et al. 2001). This leads to decreased expression of GLUT 4, the insulin-sensitive glucose transport protein (Stephens \& 
Pekala 1991). Insulin resistance in PCOS is also a postreceptor defect, and increased serine phosphorylation is implicated as the cause of decreased insulin-stimulated IRS-1 activation and decreased GLUT 4 expression (Rosenbaum et al. 1993, Dunaif et al. 2001, Li et al. 2002, Corbould et al. 2005). Thus, the ability of TNF $\alpha$ to stimulate increased serine phosphorylation makes it an ideal candidate for initiating these molecular events in PCOS.

We have previously reported that circulating levels of TNF $\alpha$ are elevated in PCOS (González et al. 1999). A likely source of excess circulating TNF $\alpha$ in obese women with PCOS is adipose tissue, but the source remains unknown in lean women with the disorder. MNC are known to migrate into adipose tissue to activate adipocyte TNFa production (Weisberg et al. 2003, Wellen \& Hotamisligil 2003). It is now clear that the major source of TNF $\alpha$ in adipose tissue of the obese is MNC-derived macrophages present in the stromal-vascular compartment (Weisberg et al. 2003, Xu et al. 2003, Fain et al. 2004a, 2004b). Thus, MNC may be an additional source of excess circulating TNF $\alpha$ in PCOS.

In the present study, we evaluated an in vitro model of hyperglycemia to determine the effect of direct exposure to hyperglycemia on TNF $\alpha$ release from MNC of women with PCOS. We hypothesized that TNF $\alpha$ release from MNC is increased in women with PCOS compared with weight-matched controls in response to hyperglycemic conditions, and that there is a relationship between measures of adiposity and MNC-derived TNF $\alpha$ release.

\section{Materials and Methods}

\section{Subjects}

Twelve women with PCOS (six lean and six obese) aged 21-34 years and 12 weight-matched control subjects (six lean and six obese) aged 20-38 years volunteered to participate in the study. The women with PCOS were diagnosed on the basis of oligoamenorrhea and hyperandrogenemia after excluding nonclassic congenital adrenal hyperplasia, Cushing's syndrome, hyperprolactinemia and thyroid disease. Polycystic ovaries were present on ultrasound in all subjects with PCOS. All control subjects were ovulatory as evidenced by regular menses and a luteal phase serum progesterone level greater than $5 \mathrm{ng} / \mathrm{ml}$. All control subjects exhibited normal circulating androgen levels and the absence of polycystic ovaries on ultrasound.

All subjects were screened for diabetes or inflammatory illnesses, and none were taking medications that affect carbohydrate metabolism or immune function for at least 6 weeks prior to study participation. None of the subjects were involved in any regular exercise program for at least 6 months before the time of testing. All of the subjects provided written, informed consent in accordance with the Case Western Reserve University and MetroHealth Medical Center guidelines for the protection of human subjects.

\section{Study design}

All study subjects underwent the oral glucose tolerance test (OGTT) on days 5 and 8 after the onset of menses. Before the OGTT, they were provided with a healthy diet consisting of $50 \%$ carbohydrate, $35 \%$ fat and $15 \%$ protein for 3 consecutive days (days 1-3) before the test. The test was performed on the morning of day 4 after an overnight fast of $\sim 12 \mathrm{~h}$. All subjects also underwent body composition assessment on the same day the OGTT was performed.

\section{Oral glucose tolerance test (OGTT)}

Fasting baseline blood samples $(5 \mathrm{ml}$ each) were drawn for glucose and insulin determination. A $75 \mathrm{~g}$ glucose beverage was subsequently ingested over $10 \mathrm{~min}$. Blood samples $(5 \mathrm{ml}$ each) were again drawn for glucose and insulin determination $2 \mathrm{~h}$ after glucose ingestion. Upon completion of the test, subjects were fed a highcarbohydrate snack. Plasma glucose concentrations were assayed immediately from the blood samples collected. Additional plasma was isolated from the fasting blood samples and stored at $-70{ }^{\circ} \mathrm{C}$ until assayed for C-reactive protein (CRP) and TNFa. Glucose tolerance was assessed by the WHO criteria with normal glucose tolerance defined as a 2-h glucose-stimulated value less than $140 \mathrm{mg} / \mathrm{dl}$, impaired glucose tolerance as a $2-\mathrm{h}$ value of 140-199 mg/dl, and type 2 diabetes mellitus defined as a 2-h value of $200 \mathrm{mg} / \mathrm{dl}$ or greater (Modan et al. 1989). Insulin sensitivity was estimated by IS $_{\text {HOMA }}$ by the following formula (Matthews et al. 1985): fasting glucose $\times$ fasting insulin/22.5.

\section{Body composition assessment}

Height without shoes was measured to the nearest $1 \cdot 0 \mathrm{~cm}$. Body weight was measured to the nearest $0 \cdot 1 \mathrm{~kg}$. Waist circumference was measured at the level of the umbilicus and used to estimate abdominal adiposity (Kohrt et al. 1993). In addition, all subjects underwent dual energy absorptiometry (DEXA) to determine percent total body fat and percent truncal fat with the QDR 4500 Elite model scanner (Hologic, Waltham, MA, USA). Truncal fat content was defined as the area between the dome of the diaphragm (cephalad limit) and the top of the greater trochanter (caudal limit) (Taylor et al. 1998).

\section{Analytic methods}

MNC isolation and culture were performed on a $20 \mathrm{ml}$ fasting blood sample drawn before ingestion of the 
Table 1 Subject characteristics

\begin{tabular}{|c|c|c|c|c|}
\hline & \multicolumn{2}{|l|}{ Control } & \multicolumn{2}{|l|}{ PCOS } \\
\hline & Lean $(n=6)$ & Obese $(n=6)$ & Lean $(n=6)$ & Obese $(n=6)$ \\
\hline Age (years) & $33 \pm 2$ & $30 \pm 3$ & $26 \pm 2$ & $28 \pm 2$ \\
\hline Height $(\mathrm{cm})$ & $165 \cdot 6 \pm 1 \cdot 0$ & $163 \cdot 1 \pm 3 \cdot 6$ & $165 \cdot 4 \pm 3 \cdot 9$ & $165 \cdot 7 \pm 2 \cdot 4$ \\
\hline Body weight (kg) & $59 \cdot 1 \pm 2 \cdot 2$ & $91 \cdot 9 \pm 4 \cdot 7^{a, b}$ & $63 \cdot 9 \pm 3 \cdot 5$ & $96 \cdot 8 \pm 6 \cdot 0^{c, d}$ \\
\hline Body-mass index $\left(\mathrm{kg} / \mathrm{m}^{2}\right)$ & $21 \cdot 6 \pm 0 \cdot 8$ & $34 \cdot 5 \pm 1 \cdot 2^{\mathrm{a}}$ & $23 \cdot 3 \pm 0 \cdot 5$ & $35 \cdot 2 \pm 1 \cdot 6^{c, d}$ \\
\hline Total body fat (\%) & $27 \cdot 1 \pm 1 \cdot 8$ & $43 \cdot 8 \pm 0 \cdot 4^{a, b}$ & $30 \cdot 7 \pm 1 \cdot 7$ & $44 \cdot 2 \pm 1 \cdot 0^{\mathrm{c}, \mathrm{d}}$ \\
\hline Truncal fat $(\%)$ & $22 \cdot 8 \pm 2 \cdot 4$ & $43 \cdot 2 \pm 0 \cdot 6^{\mathrm{a}, \mathrm{b}}$ & $29 \cdot 7 \pm 2 \cdot 6^{\mathrm{e}}$ & $45 \cdot 2 \pm 0 \cdot 9^{c, d}$ \\
\hline Waist circumference $(\mathrm{cm})$ & $71 \cdot 3 \pm 2 \cdot 0$ & $101 \cdot 1 \pm 3 \cdot 4^{\mathrm{a}, \mathrm{b}}$ & $78 \cdot 0 \pm 2 \cdot 7$ & $96 \cdot 2 \pm 8 \cdot 0^{\mathrm{c}, \mathrm{d}}$ \\
\hline
\end{tabular}

Values are expressed as means \pm S.E. ${ }^{a}$ Obese controls vs lean controls, $P<0 \cdot 0003 ;{ }^{b}$ Obese controls vs

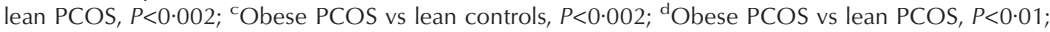
eLean PCOS vs lean controls, $P<0 \cdot 02$.

glucose beverage during the OGTT. The cells were isolated by Histopaque-1077 density gradient centrifugation (Boyam 1968), washed two times in pyrogen-free saline, re-suspended in RPMI $(0.3 \mathrm{mg} / \mathrm{ml} \mathrm{L}$-glutamine, $100 \mathrm{U} / \mathrm{ml}$ penicillin and $100 \mu \mathrm{g} / \mathrm{ml}$ streptomycin) with serum substitute $\mathrm{TCH}$, and seeded in coated culture plates $\left(2 \cdot 510^{6} \mathrm{cells} / \mathrm{ml}\right)$. The culture medium was supplemented with D-glucose at varying concentrations to mimic a euglycemic $(5 \mathrm{mM})$ or hyperglycemic (10 or $15 \mathrm{mM}$ ) environment. The cells were incubated (humidified, 5\% $\left.\mathrm{CO}_{2}, 37^{\circ} \mathrm{C}\right)$ for $24 \mathrm{~h}$. Cell supernatants were subsequently collected $(10000 \mathrm{~g}$ for $2 \mathrm{~min}$ ) and stored at $-70{ }^{\circ} \mathrm{C}$ until analysis. Plasma glucose concentrations were measured by the glucose oxidase method (YSI, Yellow Springs, OH, USA), while plasma insulin concentrations were measured by double-antibody RIA (Linco Research, St Charles, MO, USA). Plasma CRP concentrations were measured by high-sensitivity ELISA (Alpha Diagnostics International, San Antonio, TX, USA). TNF $\alpha$ concentrations were also measured by ELISA (BioSource International, Camarillo, CA, USA). All samples from each subject were measured in duplicate in the same assay. The interassay and intra-assay coefficients of variation for all assays were $7 \%$ and $12 \%$ respectively.

\section{Statistics}

The StatView statistical package (SAS Institute, Cary, NC, USA) was used for data analysis. The difference in values under either hyperglycemic condition $(10$ or $15 \mathrm{mM})$ and the euglycemic baseline $(5 \mathrm{mM})$ for primary dependent variables, such as TNF $\alpha$ release from MNC, was calculated to represent the incremental change. Descriptive data and the incremental change of variables were compared between groups by unpaired Student's t-test or ANOVA for multiple-group comparisons followed by post hoc analysis. Differences between the incremental change of variables within groups were analyzed by paired Student's $t$-test. Alterations in TNF $\alpha$ release from MNC within groups were expressed as the percent change between either hyperglycemic condition (10 or $15 \mathrm{mM}$ ) and the euglycemic condition (5 mM, 100\% baseline). Differences in the MNC-derived TNF $\alpha$ response among the different glycemic conditions within groups were analyzed by repeated-measures ANOVA. Regression analyses used the Pearson $(r)$ correlation for parametric data and the Spearman rank order $(\rho)$ correlation for nonparametric data. All values are expressed as means \pm S.E.M. An $\alpha$-level of 0.05 was used to determine statistical significance.

\section{Results}

Age and height were similar among groups (Table 1). Weight, body-mass index (BMI), percent total body fat and waist circumference were significantly $(P<0 \cdot 01)$ greater in obese subjects than in those who were lean whether or not they had PCOS, but were similar when women with PCOS were compared with weightmatched controls. The obese also exhibited significantly $(P<0 \cdot 01)$ greater percent truncal fat than lean subjects whether or not they had PCOS. However, percent truncal fat was significantly $(P<0 \cdot 02)$ greater in lean women with PCOS than in lean controls.

Circulating levels of $\mathrm{LH}$, testosterone and androstenedione were significantly $(P<0 \cdot 05)$ higher in women with PCOS than in control subjects independently of body weight (Table 2). Circulating DHEA-S levels were modestly higher in women with PCOS than in weight-matched controls. Levels of glucose while fasting and $2 \mathrm{~h}$ after glucose ingestion were similar in women with PCOS to those of controls independently of body mass. All 12 control subjects had a normal glucose response during the OGTT with $2-\mathrm{h}$ glucose levels of $62-138 \mathrm{mg} / \mathrm{dl}$. Glucose values at $2 \mathrm{~h}$ were consistent with impaired glucose tolerance in two lean women with PCOS (141 and $148 \mathrm{mg} / \mathrm{dl}$ ) and one obese woman with PCOS $(192 \mathrm{mg} / \mathrm{dl})$. Fasting insulin levels 
Table 2 Plasma hormone, glucose, insulin and C-reactive protein (CRP) levels

\begin{tabular}{|c|c|c|c|c|}
\hline & \multicolumn{2}{|l|}{ Control } & \multicolumn{2}{|l|}{ PCOS } \\
\hline & Lean $(n=6)$ & Obese $(n=6)$ & Lean $(n=6)$ & Obese $(n=6)$ \\
\hline $\mathrm{LH}(\mathrm{mlU} / \mathrm{ml})$ & $3 \cdot 3 \pm 0 \cdot 4$ & $2 \cdot 6 \pm 0 \cdot 3$ & $14 \cdot 4 \pm 1 \cdot 7^{\mathrm{a}, \mathrm{b}, \mathrm{c}}$ & $7 \cdot 6 \pm 1 \cdot 2$ \\
\hline Testosterone $(\mathrm{ng} / \mathrm{dl})$ & $42 \cdot 8 \pm 5 \cdot 8$ & $32 \cdot 7 \pm 6 \cdot 2$ & $72 \cdot 2 \pm 6 \cdot 7^{\mathrm{a}, \mathrm{b}}$ & $67 \cdot 7 \pm 7 \cdot 4^{\mathrm{d}, \mathrm{e}}$ \\
\hline Androstendione $(\mathrm{ng} / \mathrm{ml})$ & $1 \cdot 8 \pm 0 \cdot 2$ & $2 \cdot 0 \pm 0 \cdot 1^{b}$ & $3 \cdot 2 \pm 0 \cdot 4^{a, b}$ & $2 \cdot 9 \pm 0 \cdot 3^{\mathrm{d}, \mathrm{e}}$ \\
\hline DHEA-S $(\mu \mathrm{g} / \mathrm{dl})$ & $167 \pm 20$ & $205 \pm 29$ & $319 \pm 76$ & $322 \pm 67$ \\
\hline Fasting glucose $(\mathrm{mg} / \mathrm{dl})$ & $85 \cdot 3 \pm 2 \cdot 0$ & $84 \cdot 3 \pm 3 \cdot 2$ & $83 \cdot 3 \pm 3 \cdot 2$ & $87 \cdot 8 \pm 1 \cdot 9$ \\
\hline 2 -h glucose $(\mathrm{mg} / \mathrm{dl})$ & $99 \cdot 0 \pm 11 \cdot 8$ & $121 \cdot 8 \pm 6 \cdot 0$ & $112 \cdot 5 \pm 11 \cdot 2$ & $113 \cdot 5 \pm 16 \cdot 4$ \\
\hline Insulin $(\mu \mathrm{IU} / \mathrm{ml})$ & $8 \cdot 5 \pm 1 \cdot 2$ & $13 \cdot 7 \pm 2 \cdot 5$ & $11 \cdot 5 \pm 2 \cdot 1$ & $18 \cdot 6 \pm 3 \cdot 5$ \\
\hline CRP $(\mathrm{ng} / \mathrm{ml})$ & $219 \pm 92$ & $6935 \pm 139^{f}$ & $1314 \pm 412^{\mathrm{b}, \mathrm{c}}$ & $6988 \pm 1711^{\mathrm{e}}$ \\
\hline $\mathrm{IS}_{\text {HOMA }}$ & $32 \cdot 1 \pm 4 \cdot 5$ & $52 \cdot 8 \pm 10 \cdot 7$ & $43 \cdot 1 \pm 8 \cdot 6^{\mathrm{e}}$ & $73 \cdot 7 \pm 14 \cdot 8^{\mathrm{e}}$ \\
\hline
\end{tabular}

Values are expressed as means \pm S.E. ${ }^{a}$ Lean PCOS vs lean controls, $P<0 \cdot 005 ;{ }^{b}$ Lean PCOS vs obese controls, $P<0 \cdot 003$; ' Lean PCOS vs obese PCOS, $P<0 \cdot 05$; ${ }^{\mathrm{d}}$ Obese PCOS vs obese controls, $P<0 \cdot 02$; ${ }^{e}$ Obese PCOS vs lean controls, $P<0 \cdot 05$; ${ }^{f}$ Obese controls vs lean controls, $P<0 \cdot 0005$.

were modestly higher, and plasma CRP levels were significantly higher $(P<0 \cdot 05)$ in the obese whether or not they had PCOS (Table 2). CRP levels were also modestly elevated in lean women with PCOS compared with lean controls.

IS $_{\text {HOMA }}$ was significantly $(P<0 \cdot 05)$ higher in obese women with PCOS than in lean controls and lean women with PCOS (Table 2). Lean women with PCOS exhibited an $\mathrm{IS}_{\mathrm{HOMA}}$ that was similar to that of obese controls and lean controls. $\mathrm{IS}_{\mathrm{HOMA}}$ was positively correlated with BMI $(r=0.58, P=0.004)$, percent body fat $(r=0.49$, $P<0 \cdot 02)$ and percent truncal fat $(r=0 \cdot 57, P<0 \cdot 004)$ for the combined groups (data not shown).

TNF $\alpha$ release from MNC under euglycemic conditions $(5 \mathrm{mM})$ was similar in women with PCOS compared with controls (Table 3). After exposure of MNC to hyperglycemia at the $10 \mathrm{mM}$ glucose concentration, the incremental change in TNF $\alpha$ release of women with PCOS increased significantly $(P<0.03)$ compared with that of controls, which slightly declined $(7 \cdot 0 \pm 3 \cdot 3$ vs $-2 \cdot 9 \pm 2 \cdot 2)$. When subjects were grouped by body mass, the incremental change in TNF $\alpha$ release from MNC exposed to $10 \mathrm{mM}$ glucose increased significantly in obese women with PCOS compared with either lean controls $(P<0 \cdot 005)$ or obese controls $(P<0 \cdot 05)$. In contrast, the incremental change in TNF $\alpha$ release from MNC of lean women with PCOS was similar to lean controls after the $10 \mathrm{mM}$ glucose exposure. There were no significant differences in the TNF $\alpha$ response of women with PCOS compared with control subjects regardless of body weight after exposure of MNC to $15 \mathrm{mM}$ glucose.

The percent change in TNF $\alpha$ release from MNC in control subjects remained unchanged under hyperglycemic conditions $(10 \mathrm{mM}, 103 \pm 20 \% ; 15 \mathrm{mM}$, $136 \pm 33 \%$ ) compared with the euglycemic condition (5 mM, 100\%). In contrast, the women with PCOS exhibited a significant $(P<0.02)$ progressive increase in the percent change in TNFa release from MNC under hyperglycemic conditions compared with the euglycemic condition. The MNC-derived TNF $\alpha$ response to hyperglycemia was significantly greater in women with PCOS (10 mM， $410 \pm 124 \%, \quad P<0 \cdot 03 ; 15 \mathrm{mM}, 541 \pm 200 \%$, $P<0 \cdot 05)$ than in controls. When subjects were grouped by body mass, lean controls exhibited no difference in the percent change in TNF $\alpha$ release from MNC under hyperglycemic conditions compared with the euglycemic condition (Fig. 1). Obese controls and lean women with PCOS exhibited a modest increase in the percent change in

Table 3 TNF $\alpha$ release from mononuclear cells (MNC) under euglycemic and hyperglycemic conditions in vitro

\begin{tabular}{|c|c|c|c|c|c|}
\hline & $5 \mathrm{mM}$ & $10 \mathrm{mM}$ & $\Delta$ & $15 \mathrm{mM}$ & $\Delta$ \\
\hline \multicolumn{6}{|l|}{ MNC TNF $\boldsymbol{\alpha}(\mathrm{pg} / \mathrm{ml})$} \\
\hline Lean controls $(n=6)$ & $9 \cdot 4 \pm 4 \cdot 1$ & $3 \cdot 6 \pm 0 \cdot 8$ & $-5 \cdot 8 \pm 4 \cdot 0$ & $6 \cdot 4 \pm 1 \cdot 8$ & $-3 \cdot 0 \pm 2 \cdot 7$ \\
\hline Obese controls $(n=6)$ & $4 \cdot 5 \pm 1 \cdot 4$ & $4 \cdot 5 \pm 1 \cdot 5$ & $0 \cdot 02 \pm 1 \cdot 6$ & $8 \cdot 5 \pm 5 \cdot 3$ & $8 \cdot 5 \pm 5 \cdot 3$ \\
\hline Lean PCOS $(n=6)$ & $3 \cdot 0 \pm 0 \cdot 4$ & $5 \cdot 4 \pm 1 \cdot 8$ & $2 \cdot 4 \pm 1 \cdot 6$ & $7 \cdot 9 \pm 4 \cdot 5$ & $4 \cdot 9 \pm 4 \cdot 5$ \\
\hline Obese PCOS $(n=6)$ & $3 \cdot 0 \pm 0 \cdot 7$ & $14 \cdot 5 \pm 6 \cdot 1$ & $11 \cdot 6 \pm 6 \cdot 0^{a, b}$ & $21 \cdot 9 \pm 13 \cdot 6$ & $19 \cdot 0 \pm 13 \cdot 3$ \\
\hline
\end{tabular}

Values are expressed as means \pm S.E. $\Delta$ : calculated differences between TNF $\alpha$ concentrations under either hyperglycemic condition (10 or $15 \mathrm{mM})$ and euglycemic baseline $(5 \mathrm{mM})$.

${ }^{\mathrm{a}}$ Obese PCOS vs lean controls, $P<0 \cdot 005$; ${ }^{\mathrm{b}}$ Obese PCOS vs obese controls, $P<0 \cdot 05$. 


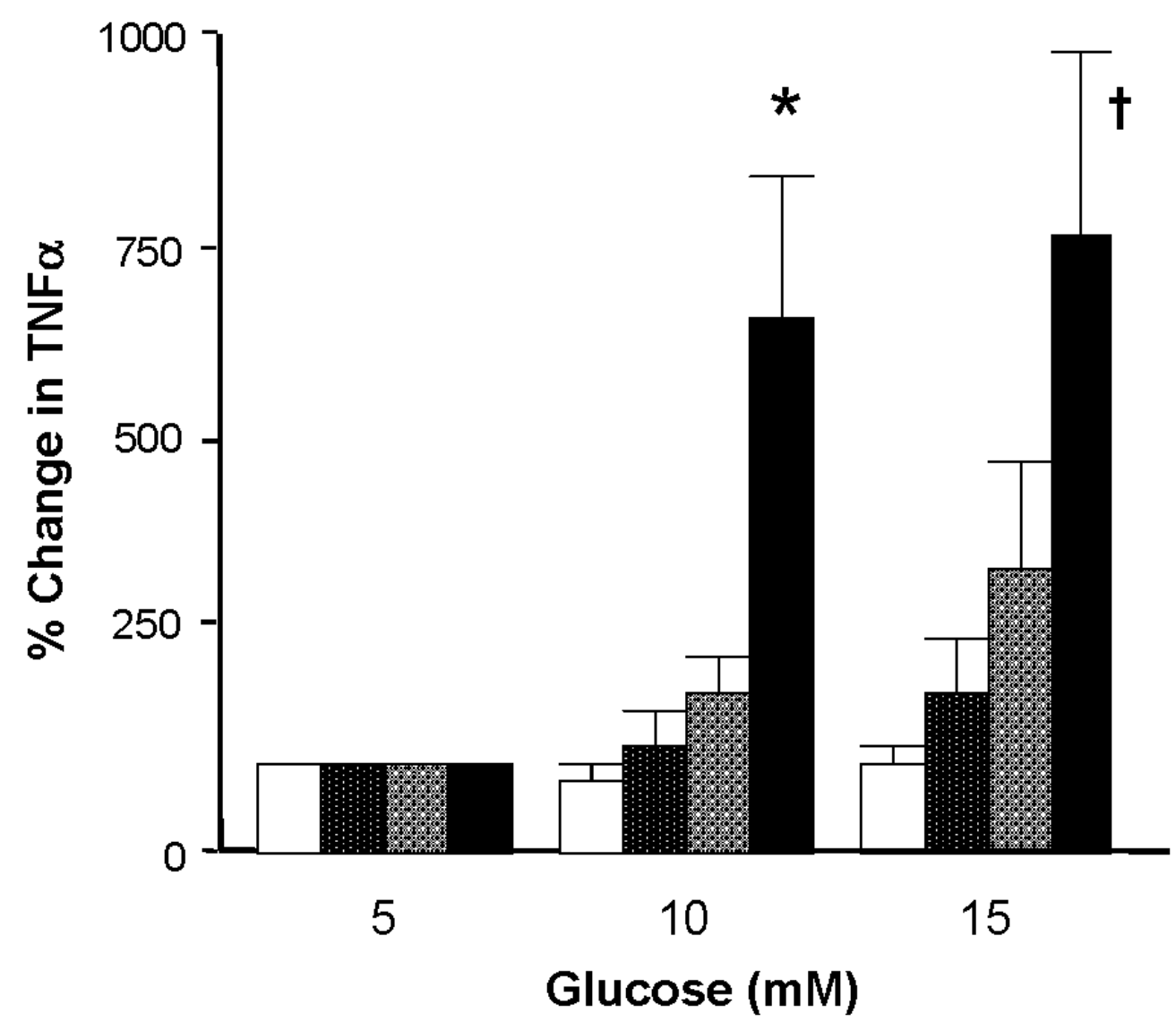

Figure 1 Percent change in TNF $\alpha$ release from MNC under hyperglycemic conditions (10 and $15 \mathrm{mM}$ ) compared with the eugylcemic condition ( $5 \mathrm{mM}, 100 \%$ baseline). $\square$ : lean controls; 빱: lean women with PCOS; $\quad$ : obese women with PCOS. ${ }^{*} \mathrm{TNF} \alpha$ response from MNC exposed to $10 \mathrm{mM}$ glucose was significantly higher in obese women with PCOS than in either control group $(P<0 \cdot 003)$. †TNF $\alpha$ response from $M N C$ exposed to $15 \mathrm{mM}$ glucose was significantly higher in obese women with PCOS than in either control group $(P<0 \cdot 04)$.

$\mathrm{TNF} \alpha$ release from $\mathrm{MNC}$ in response to hyperglycemia compared with lean controls. However, there was a significant increase in the MNC-derived TNF $\alpha$ response to hyperglycemia in obese women with PCOS $(10 \mathrm{mM}, P<0 \cdot 003$; $15 \mathrm{mM}, P<0 \cdot 04)$ compared with either control group.

After exposure of MNC to hyperglycemia at the $10 \mathrm{mM}$ glucose concentration, the percent change in $\mathrm{TNF} \alpha$ release from MNC was positively correlated with BMI, percent truncal fat and IS $_{\text {HOMA }}$ for the combined groups, and with BMI for women with PCOS (Table 4). The percent change in TNF $\alpha$ release from MNC was also positively correlated with androstenedione for the combined groups after exposure to both 10 and $15 \mathrm{mM}$ glucose, and for women with PCOS after exposure to $15 \mathrm{mM}$ glucose. The percent change in TNF $\alpha$ release from MNC and testosterone were positively correlated for women with PCOS after exposure to $15 \mathrm{mM}$ glucose, and negatively correlated for controls after exposure to both 10 and $15 \mathrm{mM}$ glucose.

\section{Discussion}

Our data clearly show that in vitro exposure to hyperglycemia causes an increase in TNF $\alpha$ release from MNC of obese women with PCOS. The in vitro conditions demonstrate that the enhanced TNF $\alpha$ response is directly related to hyperglycemia, and occurs at a glucose concentration similar to the postprandial state $(10 \mathrm{mM})$ or higher $(15 \mathrm{mM})$. The TNF $\alpha$ response is directly related to the degree of insulin resistance and to the levels of androgens. Since TNF $\alpha$ is a proinflammatory cytokine, these findings provide further support for the role of inflammation in the development of insulin resistance and hyperandrogenism in PCOS. TNFa, in particular, may contribute to the decline in insulin action in obese women with PCOS. Furthermore, the association of TNF $\alpha$ with BMI, percent total body fat and percent truncal fat suggests that the combination of PCOS and increased adiposity may be a key determinant of the MNC-derived TNF $\alpha$ response 
Table 4 Spearman rank correlation analysis examining the relationship between the percent change in TNF $\alpha$ release from mononuclear cells and $\mathrm{BMI}$, percent total body fat, percent truncal fat, $\mathrm{IS}_{\mathrm{HOMA}}$, testosterone and androstenedione

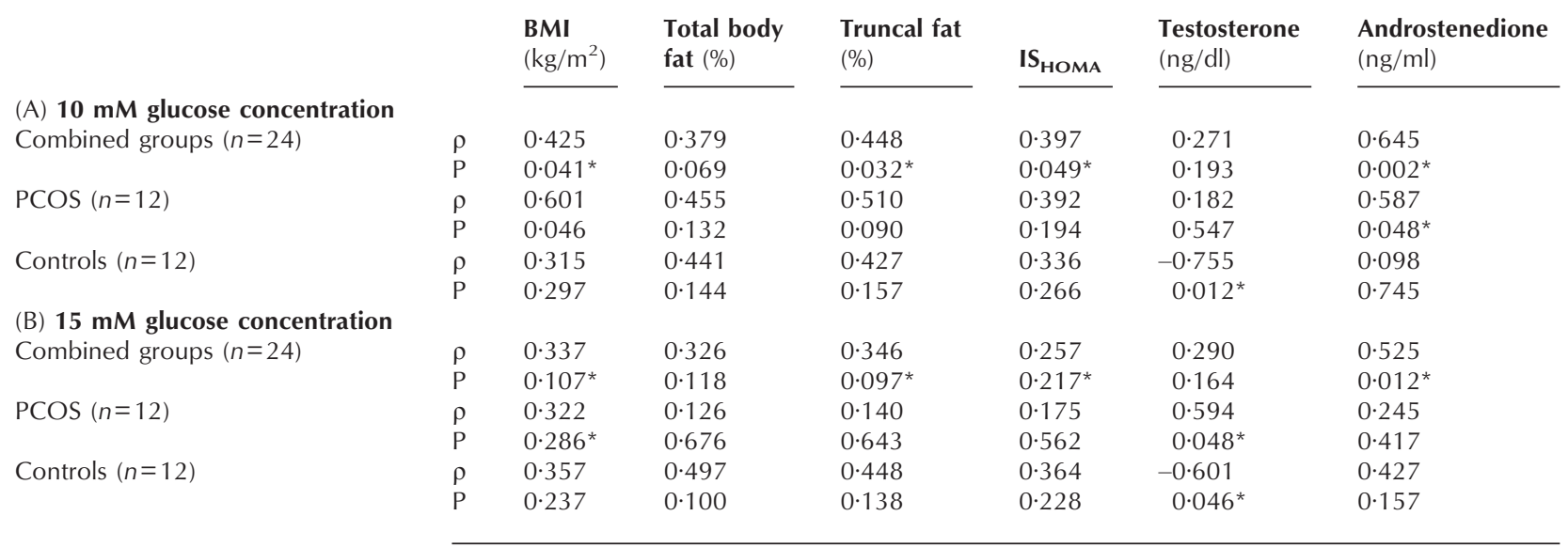

The percent change in TNF $\alpha$ release was determined by comparing the (A) $10 \mathrm{mM}$ or (B) 15 mM hyperglycemic condition with the 5 mM euglycemic condition. ${ }^{*} P<0 \cdot 05$.

observed in obese women with PCOS, and its potential role in inducing insulin resistance in these individuals.

Hyperglycemia within the physiologic range does not result in increased TNF $\alpha$ release from MNC in normal circumstances. Lean controls in the present study exhibited no change in MNC-derived TNF $\alpha$ release in response to either hyperglycemic culture condition. This is in contrast to a previous report of increases in TNFa release from MNC of normal individuals exposed to hyperglycemia in vitro (Morohoshi et al. 1996). In this study, however, the glucose concentration required to achieve this response was above the physiologic range. Since TNFa is a known mediator of insulin resistance (Hotamisligil et al. 1994, 1995, Del Aguila et al. 1999), the lack of increase in TNF $\alpha$ release from MNC may be a physiologic benefit in the presence of hyperglycemia. Thus, facilitation of glucose disposal in lean controls may be due to the control of TNF $\alpha$ release to optimize insulin signaling in the postprandial state.

In contrast, the MNC of obese women with PCOS have increased sensitivity to hyperglycemic conditions in the physiologic range. Obese women with PCOS are in a proinflammatory state, as shown by the elevations of plasma CRP observed in this group that are consistent with previous reports (Kelly et al. 1996, Bastard et al. 1999, Yudkin et al. 1999). MNC-derived TNF $\alpha$ release increased in response to either hyperglycemic culture condition in obese women with PCOS compared with obese controls. Oral intake of glucose, lipid and protein has been noted to elicit similar proinflammatory responses in vivo (Mohanty et al. 2000, 2002, Aljada et al. 2004). It is possible that in obese women with PCOS, feeding results in increased TNF $\alpha$ release from MNC in the postprandial state to promote the insulin resistance observed in these individuals. This concept is supported by the positive correlation between the TNF $\alpha$ response and IS $_{\text {HOMA }}$. Previous reports of a reduction in oxidative stress and inflammatory mediators after caloric restriction in the obese, and after a 2-day fast in normal subjects provide further corroboration (Dandona et al. 1998, 2001a, 2001b).

Our data suggest a link between adiposity and MNC-derived TNF $\alpha$ release in PCOS. There was a direct relationship between the change in TNF $\alpha$ release from MNC under hyperglycemic culture conditions and abdominal adiposity. It is possible that the inflamed adipose tissue in the abdominal region of obese women with PCOS perpetuates the increased sensitivity of MNC to hyperglycemia manifested by the increased TNF $\alpha$ release observed in culture. Our data also demonstrate a direct relationship between the degree of insulin resistance by IS $_{\text {HOMA }}$ and abdominal adiposity. These findings are consistent with previous observations in young adults demonstrating that changes in insulin sensitivity are a function of abdominal adiposity (Kriktetos et al. 2004, Linne 2004). Thus, increased TNF $\alpha$ release from MNC may promote the insulin resistance observed in obese women with PCOS.

The MNC of obese controls and lean women with PCOS exhibited only modest increases in TNF $\alpha$ release in response to hyperglycemia. Both of these groups are in a proinflammatory state, as evidenced by the elevated CRP concentrations in accordance with previous observations (Kelly et al. 1996, Boulman et al. 2004). The lack of statistical significance in the increases in TNF $\alpha$ release in either of these groups and the elevated CRP concentrations in lean women with PCOS may be due to the small sample size. Nevertheless, there is a stepwise increasing trend in the TNF $\alpha$ response, with progressively higher 
hyperglycemic conditions when study subjects are grouped by body weight. It is possible that the increased abdominal adiposity observed in lean women with PCOS also perpetuates increases in hyperglycemia-induced TNF $\alpha$ release from MNC to promote insulin resistance in this group. Nevertheless, the presence of PCOS in combination with a greater amount of adiposity may explain the higher TNF $\alpha$ response and greater degree of insulin resistance evident in obese women with PCOS.

In PCOS, TNF $\alpha$ release from $\mathrm{MNC}$ in response to hyperglycemia may be capable of directly stimulating hyperandrogenism. This is suggested by the direct correlation of the TNF $\alpha$ response with plasma levels of testosterone and androstenedione in women with PCOS. We have also demonstrated direct correlations of ROS generation (González et al. 2006) and activated NFKB (unpublished data) with these androgen levels. Infiltration of the ovary by MNC-derived macrophages has been previously reported (Best et al. 1996). Ovarian steroidogenic enzymes responsible for androgen production are stimulated by oxidative stress and inhibited by antioxidants, such as statins, in vitro (Piotrowski et al. 2005, Rzepczynska et al. 2005). Circulating androgen levels decline in women with PCOS in response to statin therapy in vivo (Banaszewska et al. 2005). TNF $\alpha$ stimulates in vitro proliferation of androgen-producing theca cells (Spazynsky et al. 1999). Thus, it is attractive to consider that increased TNF $\alpha$ release from glucose-activated MNC recruited into the polycystic ovary may be the result of a local inflammatory response that stimulates ovarian androgen production in women with PCOS.

In conclusion, MNC of obese women with PCOS exhibit increased TNF $\alpha$ response when directly exposed to hyperglycemic conditions in vitro in the physiologic range. Our findings suggest that the increased abdominal adiposity in women with PCOS promotes a proinflammatory state, especially in those who are obese. The associations of the TNF $\alpha$ response with measures of adiposity and androgen levels suggest that MNC-derived $\mathrm{TNF} \alpha$ release contributes to insulin resistance and hyperandrogenism, particularly when the combination of PCOS and increased adiposity is present.

\section{Acknowledgement}

We thank the nursing staff of the General Clinical Research Center for supporting the implementation of the study and assisting with data collection.

\section{Funding}

This research was supported by National Institutes of Health Grants HD-01273 (Women's Reproductive Health Research Program) to the Department of
Obstetrics and Gynecology at MetroHealth Medical Center and MO1 RR-000080 to the General Clinical Research Center. The authors declare that there is no conflict of interest that would prejudice the impartiality of this scientific work.

\section{References}

Aljada A, Mohanty P, Ghanim H, Abdo T, Tripathy D, Chaudari A \& Dandona P 2004 Increase in intranuclear nuclear factor kappa B and decrease in inhibitor kappa B in mononuclear cells after a mixed meal: evidence for a proinflammatory effect. American Journal of Clinical Nutrition 79 682-690.

Banaszewska B, Pawelczyk L, Spaczynski RZ, Dziura J \& Duleba AJ 2005 Simvastatin improves hyperandrogenism, hyperandrogenemia, LH and lipid profile in women with PCOS: a randomized cross-over study. Fertility and Sterility 84 Suppl 1 S54-S55.

Barnes PJ \& Karin M 1997 Nuclear factor- $\kappa B$ : a pivotal transcription factor in chronic inflammatory diseases. New England Journal of Medicine 336 1066-1071.

Bastard JP, Jardel C, Delattre J, Hainque B, Bruckert E \& Oberlin F 1999 Evidence for a link between adipose tissue interleukin-6 content and serum C-reactive protein concentrations in obese subjects. Circulation 99 2221-2222.

Best CL, Pudney J, Welch WR, Burger N \& Hill JA 1996 Localization and characterization of white blood cell populations within the human ovary throughout the menstrual cycle and menopause. Human Reproduction 11 790-797.

Boulman N, Leiba LR, Shachar S, Linn R, Zinder O \& Blumenfeld Z 2004 Increased c-reactive protein levels in the polycystic ovary syndrome: a marker of cardiovascular disease. Journal of Clinical Endocrinology and Metabolism 89 2160-2165.

Boyam A 1968 Isolation of mononuclear cells and granulocytes from human blood. Scandinavian Journal of Clinical Laboratory Investigation 21 (Suppl 97) 77-89.

Burghen GA, Givens JR \& Kitabachi AE 1980 Correlation of hyperandrogenism with hyperinsulinemia in polycystic ovarian disease. Journal of Clinical Endocrinology and Metabolism 50 113-116.

Ciaraldi TP, Kolterman OG \& Olefsky JM 1981 Mechanism for the postreceptor defect in insulin action in human obesity. Decrease in glucose transport system activity. Journal of Clinical Investigation 68 875-878.

Corbould A, Kim YB, Youngren JF, Pender C, Kahn BB, Lee A \& Dunaif A 2005 Insulin resistance in the skeletal muscle of women with PCOS involves intrinsic and acquired defects in insulin signaling. American Journal of Physiology. Endocrinology and Metabolism 288 E1047-E1054.

Dandona P, Weinstock R, Thusu K, Abdel-Rahman E, Aljada A \& Wadden T 1998 Tumor necrosis factor- $\alpha$ in sera of obese patients: fall with weight loss. Journal of Clinical Endocrinology and Metabolism 83 2907-2910.

Dandona P, Mohanty P, Ghanim H, Aljada A, Browne R, Hamouda W, Prabhala A, Afzal A \& Garg R 2001a The suppressive effect of dietary restriction and weight loss in the obese on the generation of reactive oxygen species by leukocytes, lipid peroxidation, and protein carbonylation. Journal of Clinical Endocrinology and Metabolism 86 355-362.

Dandona P, Mohanty P, Hamouda W, Ghanim H, Aljada A, Garg R \& Kumar V $2001 b$ Inhibitory effect of a two day fast on reactive oxygen species (ROS) generation by leucocytes and plasma ortho-tyrosine and meta-tyrosine concentrations. Journal of Clinical Endocrinology and Metabolism 86 2899-2902.

Del Aguila LF, Claffey KP \& Kirwan JP 1999 TNF- $\alpha$ impairs insulin signaling and insulin stimulation of glucose uptake in $\mathrm{C}_{2} \mathrm{C}_{12}$ muscle cells. American Journal of Physiology. Endocrinology and Metabolism 276 E849-E855. 
Dunaif A 1999 Insulin resistance and the polycystic ovary syndrome: mechanism and implications for pathogenesis. Endocrine Reviews $18774-800$

Dunaif A, Wu X, Lee A \& Diamanti-Kandarakis E 2001 Defects in insulin receptor signaling in vivo in the polycystic ovary syndrome (PCOS). American Journal of Physiology. Endocrinology and Metabolism 281 E392-E399.

Evans JL, Goldfine ID, Maddux BA \& Grodsky GM 2002 Oxidative stress and stress-activated signaling pathways: a unifying hypothesis of type 2 diabetes. Endocrine Reviews 23 599-622.

Fain JN, Bahouth SW \& Madan AK 2004a TNF $\alpha$ release by nonfat cells of adipose tissue. International Journal of Obesity 28 616-622.

Fain JN, Madan AK, Hyler ML, Cheema P \& Bahouth SM $2004 b$ Comparison of the release of adiponectin by adipose tissue, adipose tissue matrix, and adipocytes from visceral and subcutaneous abdominal adipose tissues of obese humans. Endocrinology 145 2273-2282.

Feinstein R, Kanety H, Papa MZ, Lunenfeld B \& Karasik A 1993 Tumor necrosis factor $\alpha$ suppresses insulin-induced tyrosine phosphorylation of insulin receptor and its substrates. Journal of Biological Chemistry 268 26055-26058.

González F, Thusu K, Rahman EH, Tomani M \& Dandona P 1999 Elevated serum levels of tumor necrosis factor $\alpha$ in normal-weight women with polycystic ovary syndrome. Metabolism 48 437-441.

González F, Rote NS, Minium J \& Kirwan JP 2006 Reactive oxygen species-induced oxidative stress in the development of insulin resistance and hyperandrogenism in polycystic ovary syndrome. Journal of Clinical Endocrinology and Metabolism 91 336-340.

Goodarzi MO \& Korenman SG 2002 The importance of insulin resistance in polycystic ovary syndrome. Fertility and Sterility 77 255-258.

Hotamisligal GS, Shargill NS \& Spiegelman BM 1993 Adipose expression of tumor necrosis factor $\alpha$ : direct role in obesity linked insulin resistance. Science 259 87-91.

Hotamisligil GS, Murray DL, Choy LN \& Spiegelman BM 1994 Tumor necrosis factor $\alpha$ inhibits signaling from the insulin receptor. PNAS 1 4854-4858.

Hotamisligil GS, Arner P, Caro JF, Atkinson RL \& Speigelman BM 1995 Increased adipose tissue expression of tumor necrosis factor $\alpha$ in human obesity and insulin resistance. Journal of Clinical Investigation 95 2409-2415.

Kelly CC, Lyall H, Petrie JR, Gould GW, Connell JMC \& Sattar N 1996 Low grade chronic inflammation in women with polycystic ovary syndrome. Journal of Clinical Endocrinology and Metabolism $862453-2455$.

Knochenhauer ES, Key TJ, Kahser-Miller M, Waggoner W, Boots LR \& Azziz R 1998 Prevalence of the polycystic ovary syndrome in unselected black and white women of the southeastern United States: a prospective study. Journal of Clinical Endocrinology and Metabolism 83 3078-3082.

Kohrt WM, Kirwan JP, King DS, Staten MA \& Holloszy JO 1993 Insulin resistance of aging is related to abdominal obesity. Diabetes 42 273-281.

Kolterman OG, Insel J, Saekow M \& Olefsky JM 1980 Mechanisms of insulin resistance in human obesity. Evidence for receptor and post receptor defects. Journal of Clinical Investigation 65 1272-1284.

Kriktetos AD, Greenfield JR, Peake PW, Furler SM, Denyer GS, Charlesworth JA \& Campbell LV 2004 Inflammation, insulin resistance, and adiposity. Diabetes Care 27 2033-2040.

Li M, Youngren JF, Dunaif A, Goldfine ID, Maddux BA, Zhang BB \& Evans JL 2002 Decreased insulin receptor (IR) autophosphorylation in fibroblasts from patients with PCOS: effects of serine phosphorylation inhibitors and IR activators. Journal of Clinical Endocrinology and Metabolism 87 4088-4093.

Linne Y 2004 Effects of obesity on women's reproduction and complications during pregnancy. Obesity Reviews 5 137-143.
Matthews DR, Hosker JP, Rudenski AS, Naylor BA, Treacher DF \& Turner RC 1985 Homeostasis model assessment: insulin resistance and beta-cell function from fasting plasma glucose and insulin concentrations in man. Diabetologia 28 412-419.

Modan M, Harris MI \& Halkin H 1989 Evaluation of WHO and NDDG criteria for impaired glucose tolerance. Results from two national samples. Diabetes 38 1630-1635.

Mohanty P, Hamouda W, Garg R, Aljada A, Ghanim H \& Dandona P 2000 Glucose challenge stimulates reactive oxygen species generation by leucocytes. Journal of Clinical Endocrinology and Metabolism 85 2970-2973.

Mohanty P, Ghanim H, Hamouda W, Aljada A, Garg R \& Dandona P 2002 Both lipid and protein intakes stimulate increased generation of reactive oxygen species by polymorphonuclear leukocytes and mononuclear cells. American Journal of Clinical Nutrition 75 767-772.

Morohoshi M, Fujisawa K, Uchimura I \& Numano F 1996 Glucose-dependent interleukin 6 and tumor necrosis factor production by human peripheral blood monocytes in vitro. Diabetes 45 954-959.

Nestler JE, Jakubowicz DJ, de Vargas AF, Brik C, Quintero N \& Medina F 1998 Insulin stimulates testosterone biosynthesis by human theca cells from women with polycystic ovary syndrome by activating its own receptor and using inositoglycan mediators as the signal transduction system. Journal of Clinical Endocrinology and Metabolism 83 2001-2005.

Piotrowski PC, Rzepczynska IJ, Kwintkiewicz J \& Duleba AJ 2005 Oxidative stress induces expression of CYP11A, CYP17, STAR and $3 \beta \mathrm{HSD}$ in rat theca-interstitial cells. Journal of the Society for Gynecologic Investigation 12 (Suppl 2) 319A (Abstract).

Rosenbaum D, Haber RS \& Dunaif A 1993 Insulin resistance in polycystic ovary syndrome: decreased expression of GLUT 4 glucose transporters in adipocytes. American Journal of Physiology 264 E197-E202.

Rossetti L, Giaccari A \& DeFronzo RA 1990 Glucose toxicity. Diabetes Care 13 610-630.

Rotterdam ESHRE/ASRM-Sponsored PCOS Conference Workshop Group 2004a Revised 2003 consensus on diagnostic criteria and long-term health risks related to polycystic ovary syndrome. Fertility and Sterility 81 19-25.

Rotterdam ESHRE/ASRM-Sponsored PCOS Conference Workshop Group 2004b Revised 2003 consensus on diagnostic criteria and long-term health risks related to polycystic ovary syndrome. Human Reproduction 19 41-47.

Rui L, Aguirre V, Kim JK, Shulman GI, Lee A, Corbould A, Dunaif A \& White MF 2001 Insulin/IGF-1 and TNF- $\alpha$ stimulate phosphorylation of IRS-1 at inhibitory Ser307 via distinct pathways. Journal of Clinical Investigation 107 181-189.

Rzepczynska IJ, Piotrowski PC, Kwintkiewicz J \& Duleba AJ 2005 Effect of mevastatin on expression of CYP17, 3ßHSD, CYP11A and STAR in rat theca-interstitial cells. Journal of the Society for Gynecologic Investigation 12 (Suppl 2) 320A (Abstract).

Spazynsky RZ, Arici A \& Duleba AJ 1999 Tumor necrosis factor alpha stimulates proliferation of rat ovarian theca-interstitial cells. Biology of Reproduction 61 993-998.

Stephens JM \& Pekala PH 1991 Transcriptional repression of the GLUT 4 and C/EBP genes in 3T3-L1 adipocytes by tumor necrosis factor $\alpha$. Journal of Biological Chemistry 266 21839-21845.

Taylor RW, Keil D, Gold EJ, Williams SM \& Goulding A 1998 Body mass index, waist girth, and waist to hip ratio as indexes of total and regional adiposity in women: evaluation using receiver operating characteristic curves. American Journal of Clinical Nutrition $6744-49$.

Weisberg SP, McCann D, Desai M, Rosenbaum M, Leibel RL \& Ferrante AW Jr 2003 Obesity is associated with macrophage accumulation in adipose tissue. Journal of Clinical Investigation 112 1796-1808. 
Wellen KE \& Hotamisligil GS 2003 Obesity-induced inflammatory changes in adipose tissue. Journal of Clinical Investigation 112 1785-1788.

Xu H, Barnes GT, Yang Q, Tan G, Yang D, Chou CJ, Sole J, Nichols A, Ross JS, Tartaglia LA et al. 2003 Chronic inflammation in fat plays a crucial role in the development of obesity-related insulin resistance. Journal of Clinical Investigation 112 1821-1830.

Yki-Jarvinen H 1992 Glucose toxicity. Endocrine Reviews 13 415-431.
Yudkin JS, Stehouwer CD, Emeis JJ \& Coppack SW 1999 C-reactive protein in healthy subjects: associations with obesity, insulin resistance, and endothelial dysfunction: a potential role for cytokines originating from adipose tissue? Arteriosclerosis, Thrombosis, and Vascular Biology 19 972-978.

Received 17 November 2005

Accepted 25 November 2005 